\title{
Facies control on redox interpretations: Implications from Early Mississippian Bakken Fm.
}

\author{
DiPANWITA NANDY ${ }^{1 *}$, SWAPAN K. SAHOO ${ }^{2}$ \\ AND STEPHEN A. SONNENBERG ${ }^{1}$
}

${ }^{1 *} \mathrm{GGE}$, Colorado School of Mines,

dipanwita.nandy@shell.com (*presenting author)

${ }^{2}$ Dept of Geoscience, UNLV, swas@equinor.com

${ }^{3} \mathrm{GGE}$, Colorado School of Mines, ssonnenb@mines.edu

Early Mississippian Upper Bakken Shale (UBS) in the Williston Basin, North Dakota, USA is a world-class source rock with organic content (TOC) varying in between 3 to 20 $w t \%$. Multiple studies have resulted in contradictory interpretation of the depositional setting and paleo-redox condition. Here we present redox sensitive trace elements (RSE) data, stable isotope of $\mathrm{N} \& \mathrm{C}$, coupled with core descriptions, thin-section petrography and SEM analysis from a key well at the basin depocenter to understand the factors controlling the organic richness and depositional condition of the UBS.

Our results from RSE distribution suggests that the basin was open-to-semi-restricted with a stratified water column, and was often replete with bio-limiting nutrients - $\mathrm{P}$ and $\mathrm{N}$. However, these conditions varied during the deposition of the UBS, primarily due to a relative change in sea level, which resulted in two distinct sub-units in the UBS. Although an influx of clay had a positive effect on organic-richness, biogenic silica had a dilution effect during the deposition of organic matter in lower part of the UBS. Elemental rations and $\mathrm{Fe} / \mathrm{S}$ relationships suggest that these sediments were deposited under strongly euxinic (anoxic $+\mathrm{H}_{2} \mathrm{~S}$ ) conditions. Concurrently, the upper part of the UBS was deposited predominantly under sub-oxic water column, with marked low paleo-productivity and near crustal values for major RSE.

This lack of enrichment in a largely open-marine basin, suggests a global reservoir drawdown effect because RSE is expected to be enriched in sediments under euxinic conditions. In contrast, $\mathrm{C}$ and $\mathrm{N}$ isotopic value for organic matter trends towards a terrestrial flux, suggesting more suboxic water column deposition. Detailed microscopic analysis across each stratigraphic unit suggests that perhaps the upper UBS was more oxygenated, with the presence of bioturbation and more terrestrial signature. We conclude that careful consideration should be taken while interpretation of RSE, as facies plays an important role in redox variability. These results have important implications for understanding the global ocean redox landscape across the critical DevonianMississippian transition. 